\title{
XXIV. On fluorine
}

\section{G.J. Knox Esq. \& Rev. Thomas Knox}

To cite this article: G.J. Knox Esq. \& Rev. Thomas Knox (1836) XXIV. On fluorine, Philosophical Magazine Series 3, 9:52, 107-109, DOI: 10.1080/14786443608648958

To link to this article: http://dx.doi.org/10.1080/14786443608648958

册 Published online: 01 Jun 2009.

Submit your article to this journal ש

Џ Article views: 2

Q View related articles $\sqsubset$ 


\section{[ 107$]$}

XXIV. On Fluorine. By G. J. KNox, Esq., and the Rev. Thomas Knox.*

A $\mathrm{S}$ far as the existence of a substance which had not bitherto $A$ been procured in an independent state could be determined, the experiments and reasoning of Davy and Berzelius are sufficiently conclusive. The only desideratum seems to have been the obtaining a vessel upon which this energetic principle would exert no action. Since fluorine shows no affinity for the negative elements oxygen, chlorine, iodine, and bromine, nor for carbon or nitrogen, it would appear that the vessel to contain it should consist of some solid compound of those substances; but as such vessels would be unable to bear exposure to a high temperature, we considered that though they might be convenient for retaining the gas when once obtained, they would not answer for its production. It was therefore necessary to employ some substance already saturated with the element; and for this purpose fluor spar, from bearing exposure to a high temperature and being easily formed into vessels, appeared best adapted. The most convenient method of obtaining the gas seemed to be by acting upon fluoride of mercury with dry chlorine, by which means, if the absence of moisture could be insured and the formation of a chloride of mercury obtained, fluorine must have been disengaged, and if present would be recognised by appropriate tests.

Placing dry fluoride of mercury in the fluor-spar vessel, we heated it till a glass plate cooled by the evaporation of sulphuret of carbon showed no trace of moisture in the vessel; the chlorine was then passed through a desiccating tube filled with fused chloride of calcium, the tube being bent at an angle, and its extremity drawn capillary, so as to enter the vessel, which, when filled with the gas, had its orifice closed with a plate of fluor spar which was fastened firmly down.

After exposing it to the heat of a spirit-lamp for some time, on removing the fluor spar cover, and replacing it rapidly with one of silica, it showed immediate and powerful action. The inside of the vessel was found on examination to be covered with crystals of bichloride of mercury; both of which results prove the presence of either fluorine or hydrofluoric acid; to determine which, we repeated the experiment, cooling the cover of the vessel so as to condense any hydrofluoric acid which might be present, but none appeared, from

* Communicated by the Authors.

N 2 
which we inferred that fluorine and not hydrofluoric acid had been present in the vessel, which was also further confirmed by the absence of fumes when the vessel and its contents had been previously dried.

Placing inverted over the orifice of the vessel a clear crystal of Huor spar, with a small perforation in the centre into which a stopper of fluor spar fitted accurately, on the stopper falling into the vessel the tube was filled with a yellowish green gas, the colour of which deepened with heat, and disappeared when cold. On reheating the vessel below, the gas rose again into the crystal above. On removing the crystal while hot to a wet glass plate, it flew to pieces, which prevented us from determining whether the coloured gas was bichloride of mercury under heat and pressure, hydrofluoric acid, or fluorine.

Having procured larger vessels with receivers into which ground stoppers were made to fit accurately, we resumed in the present month the experiments we had tried in the beginning of April.

1st Exp. We heated fluoride of lead with oxygen, and afterwards with dry chlorine without action upon the fluoride. When the receiver (its stopper having fallen into the vessel below) was placed over gold-leaf, a chloride of gold was formed.

2nd Exp. Treating hydrofluate of ammonia similarly with chlorine, there was strong action on glass and formation of chloride of gold as before.

3rd Exp. Treating fluoride of mercury with chlorine (as we had done in our former experiments), we obtained crystals of bichloride of mercury in the vessel. Leaving the receiver over gold-leaf, there was after a considerable time action on it, producing a yellowish brown appearance. This we placed on a slip of glass, and on adding a few drops of sulphuric acid and evaporating to dryness there was very strong action on the glass where the gold had been, proving that it was a fluoride of gold, and that since gold is not acted on by hydrofluoric acid there must have been fluorine in the receiver. As an additional corroboration there was no hydrogen in the tube, which there would have been had hydrofluoric acid been decomposed by the gold. From these experiments we conclude that fluorine was present in the receiver, but whether a slight trace of hydrofluoric acid (to which the action on glass was due) may not have been present with it, we have not yet determined. We hope on a future occasion to be able to give particulars with regard to the properties of the gas; but we consider that 
Mr. G. Bird on certain new Combinations of Albumen. 109

the present results are sufficiently important to justify us in submitting them to the public through the medium of your Magazine.

Toomavara, Tipperary, July 1836.

T. KNox,

Geo. J. Knox.

\section{Explanation of Figures.}

Fig. 1. The vessel with the receiver in the stand which holds down the receiver by means of spiral springs $A$.

Fig. 2. Vessel with cover off, showing the orifice and the small depressions in which the gold-leaf, \&c. were placed.

Fig. 3. Receiver without stopper.

Fig. 4. The stopper.

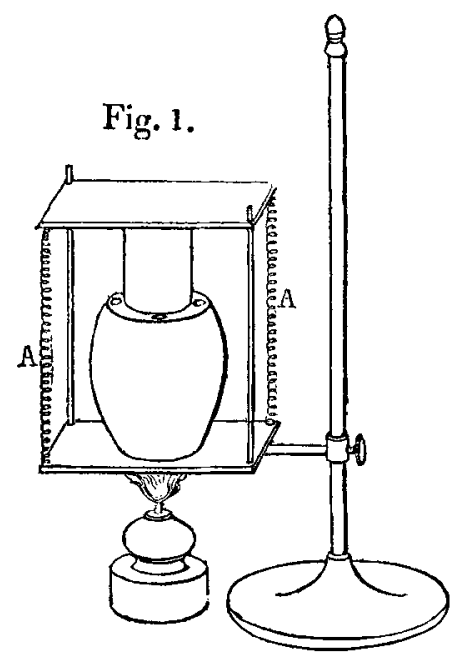

Fig. 2.

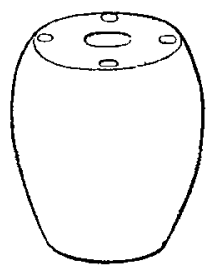

Fig. 3.

Fig. 4 .
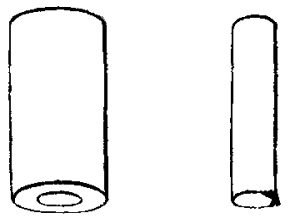

XXV. On certain nerw Combinations of Albumen, with an Account of some curious Properties peculiar to that Substance. By Golding Bird, F.L.S., F.G.S., Senior Fellow of the Physical Society of Guy's Hospital, \&c.*

1. $\mathrm{N}$ the course of the following observations I shall avoid any unnecessary reiteration of facts already well known to chemists, and confine myself to referring to them only when they are required to explain any circumstances connected with those new modifications or combinations of albumen which have fallen under my notice. Our knowledge of the properties of albumen, although more extended than that

* Communicated by the Author. 